Concerns included maintaining staff commitment and loneworking.

Conclusion and Recommendations The RWLS appears viable, two of three main aims were met. Further investigations into patient benefit and flow, cost and handover efficiency would potentially improve the justification for implementing the service long-term. Staff accepted continuing the RWLS following the trial period. Maintenance of the service may require optin rostering, and promotion of the benefits to staff in light of the potential easing of COVID-19 restrictions.

\section{P181 FINANCIAL BENEFITS OF A DEDICATED PULMONARY NODULE MULTIDISCIPLINARY TEAM MEETING: EXPERIENCE FROM A DISTRICT GENERAL HOSPITAL IN THE UNITED KINGDOM}

P Ayuen, A Khan, C Butter, R Davies, C Ashwin, S Saikia. St Peters Hospital, Chertsey, Surrey, UK

10.1136/thorax-2021-BTSabstracts. 290

Introduction and Objectives Traditionally, pulmonary nodule surveillance was clinic-based with discussions of pulmonary nodule cases at lung cancer multi-disciplinary team meetings (MDTM). However, the increased burden of nodule discussions can increase workload when discussed at complex lung cancer MDTMs. ${ }^{1}$ Thus, a dedicated pulmonary nodule MDTM was initiated at Ashford and St Peters Hospital (ASPH) NHS Trust with aim to determine its financial implications.

Methods We undertook a cost effectiveness analysis to compare the NHS cost of discussion of one nodule case at pulmonary nodule MDTM versus discussion at lung cancer MDTM at ASPH for 1 hour of time. We calculated the hourly cost for each member. The non-direct costs i.e., overheads of $21 \%$ were added to the total MDTM cost. Discussion of one case at MDTM takes 3 minutes on average i.e., 1 minute for radiology review, 1 minute for discussion and 1 minute for form filling and recording. The cost per case associated with discussion at nodule MDTM was compared to the costs per case at lung cancer MDTM and outpatient clinic review.

Abstract P181 Table 1 showing cost of each MDTM member for pulmonary nodule and lung cancer MDTM

\begin{tabular}{lllll}
\hline Lung cancer MDTM & & & \multicolumn{2}{l}{ Pulmonary nodule MDTM } \\
\hline MDTM member & MDTM & $\begin{array}{l}\text { Cost (f) per } \\
\text { hour }\end{array}$ & $\begin{array}{l}\text { MDTM } \\
\text { members }\end{array}$ & $\begin{array}{l}\text { Cost (f) per } \\
\text { hour }\end{array}$ \\
\hline Respiratory & 4 & 372.00 & 1 & 93.00 \\
consultant & & & 1 & \\
$\begin{array}{l}\text { Radiologist } \\
\text { MDT coordinator }\end{array}$ & 2 & 198.00 & 1 & 99.00 \\
$\begin{array}{l}\text { Thoracic surgeon } \\
\text { Oncologist }\end{array}$ & 2 & 15.50 & 15.50 \\
$\begin{array}{l}\text { Palliative care } \\
\text { consultant }\end{array}$ & 2 & 198.00 & 0 & 0.00 \\
$\begin{array}{l}\text { Lung cancer CNS } \\
\text { Overhead allowance }\end{array}$ & 1 & 198.00 & & 0.00 \\
$\begin{array}{l}\text { (21\%) } \\
\text { Total cost of MDT/ }\end{array}$ & $\mathrm{f1326.77}$ & 87.00 & & 0.00 \\
hour & & 28.00 & & 0.00 \\
\hline
\end{tabular}

Results The cost to discuss one case at the lung cancer MDTM was $£ 66.34$, compared to $£ 12.55$ for discussion at pulmonary nodule MDTM. Therefore, the estimated cost saving was $£ 53.79$ per case if discussed at nodule MDTM as opposed to lung cancer MDTM. The pulmonary nodule MDTMs avoided the need for outpatient clinic review and was estimated to save $£ 99.55$ per follow up case [cost of follow outpatient clinic visit (112.10) minus cost of one nodule MDTM case $(£ 12.55)]$ and $£ 238.23$ per new case [cost of new outpatient clinic visit $(£ 250.78)$ minus cost of one nodule MDTM case (12.55)].

Conclusion To conclude, the implementation of a pulmonary nodule MDTM has resulted in massive cost savings to our organisation. If this were to be formally implemented and adopted to a regular job planned activity, the cost savings to the NHS as a whole could be substantial.

\section{REFERENCE}

1. Hardavella G, Desai S. Development of a pulmonary nodule service \& clinical pathway: A pragmatic approach addressing an unmet need. European Respiratory Journal 2016:48:60. doi:10.1183/13993003.congress-2016.PA3079

\section{P182 WHAT MAKES A HERO?}

K Crowley, I Du Rand. Hereford County Hospital, Hereford, UK

\subsection{6/thorax-2021-BTSabstracts.291}

National data has shown that the COVID-19 pandemic has drastically impacted the situation of poor mental health amongst NHS staff. Severe levels of anxiety have risen from $8 \%$ pre-pandemic to $36 \%$ during the pandemic and severe stress has increased from $11 \%$ to $46 \%{ }^{1}$.

From a targeted and anonymous survey of 125 healthcare professionals at a district general hospital 83\% said that their mental health had been negatively impacted by the pandemic. Interestingly, although $72 \%$ were aware of support available for mental health just over half said that they would feel comfortable seeking this support.

Throughout the pandemic NHS workers have been praised for being 'heroes'. There are growing concerns that this label could actually be detrimental, making it more difficult for staff to seek help with their mental health and exacerbating the existing issue of mental health stigma among healthcare professionals ${ }^{2}$. This issue is visibly evident with the vast majority of survey respondents reporting a decline in mental health, but a large proportion not feeling comfortable in seeking help.

Specific factors affecting mental health were evaluated (figure 1) and the factor with the greatest response was 'fear of spreading the virus to loved ones'. Conversely the lowest response was 'fear of catching the virus yourself'. This is an example of the inbuilt compassionate nature that healthcare professionals have, but the lack of self-compassion even in times of adversity.

There is no simple or quick fix to this issue. What is needed is a shift in culture. Putting an emphasis on wellbeing, kind communication, encouraging the use of available support and compassionate leadership are just some of the ways to managed this issue long term. This pandemic will have effects lasting long after the last case is reported and the heroes in years to come will be those who knew how to seek help and felt comfortable to do so when they needed it. 